\title{
Influence of burnt ash additives on stabilisation of soft clay soils
}

\author{
K. Rangaswamy ${ }^{1}$
}

Received: 30 May 2016/ Accepted: 20 July 2016/Published online: 1 August 2016

(C) Springer International Publishing Switzerland 2016

\begin{abstract}
This paper discusses the results of the improvement in compaction, consolidation and shear strength parameters of soft clay when stabilised with burnt ash additives those derived from a furnace in the thermal power industry. Different combinations of soil-ash mixtures are prepared with the addition of ash in the range of 10-40\% by weight of soil to arrive the optimum dosage of ash which one exhibiting maximum UCS. Herein the ash additives including both the fly ash and bottom ashes are used as the stabilising agents. The influence of curing time is also studied on UCS strength property of various soil combinations. Results indicate that the stabilisation of soft clay with ash additives is improving the UCS up to certain level of ash amounts, and further the strength is decreased. The strength of soil-fly ash mixture is much more than the strength of soil-bottom ash mixture, and it was found to be 4.86 times the strength of soft clay. The mixing of ash additives in the soil could lead to speed up the time required to consolidate the clay soil and become more permeable.
\end{abstract}

Keywords Soft clay · Ash · UCS · Curing time

Electronic supplementary material The online version of this article (doi:10.1007/s41062-016-0025-8) contains supplementary material, which is available to authorized users.

\footnotetext{
K. Rangaswamy

ranga@nitc.ac.in

$1 \quad$ NIT Calicut, Kozhikode, India
}

\section{Introduction}

For structures that involve relatively light to moderate loads that are distributed over large areas, the costs associated with the use of deep foundations to bypass soft clay layers may be very high. In such cases, soil stabilisation has been successfully used to improve the mechanical properties of the soft clay. The uncontrollable usage of non-renewable natural material and the production of waste from human activities have resulted in negative impact on the earth. The utilization of by-products or waste in the construction industry is one of the methods to achieve sustainable development. According to Muhardi et al. [1], the power plant companies posed social and environmental problems to the society because of the magnification of disposal areas and the increased disposal expenses to accommodate the by-products that are transferred to end users.

Nowadays, the demand is increasing drastically to produce electricity power from thermal power plants. Each power plant is releasing a huge amount of fly ash and bottom ash as a waste by-product, and it poses difficulties for storing and preventing the environmental pollution. Hence, the present work focuses on utilizing such waste bye product as a stabilizing material to improve the properties of clay soil. Bottom ash is the heavier burnt particle settled on the lower part of a furnace in thermal power plant. It is dark greyish black in colour with sand like texture. Fly ash is the burnt finer material as similar to silt particles. Fly ash exploited in the construction of embankments, roads, reclamation of low-lying areas, fill behind retaining structures, etc. due to its low specific gravity, good drainage, and frictional properties. There are different studies performed on bottom ash as well as fly ash mixed with clay soil as an enormous potential in 
construction and soil improvement. Several studies were proved that the various geotechnical properties of stabilized clay soils improved after addition of the optimal dosage of fly ash [2-6]. However, those studies used different types of clay soils, i.e., low plastic to highly expansive clay soils were tested after adding fly ash along with other admixtures. It is observed from the above published papers that the improved geotechnical properties of stabilized clay are also depended on several factors such as the type of clay and fly ash, mixing method, curing time, PI, and other additives along with fly ash. Since 1990, a few studies were performed on clay soil stabilization using bottom ash additive [7-11].

Based on the review of previous papers, it was observed that the bottom ash and fly ash mixtures are introduced to strengthen the properties of clay soils; however, the studies are very limited on soft clay stabilization using bottom ash mixtures on the improvement of soil properties.

\section{Material characterisation}

Fly ash and bottom ash materials utilized for this study are collected from Ennore thermal power plant, Chennai, India. The clay soil used to stabilise was obtained from the local region of Kunnamangalam of Calicut city in the Kerala state of India. The soil derived was a clayey deposit at the depth of $12 \mathrm{~m}$ in already existing open cut well. All the basic geotechnical property tests were performed on untreated clay soil sample according to the Indian standard procedures, and the soil is characterized by the properties listed in Table 1.

Fly ash with the specific gravity of 2.04 is used for stabilising the soil. The optimum water content of fly ash was found to $24 \%$ corresponding to the maximum dry density of $1.2 \mathrm{~g} / \mathrm{cm}^{3}$. Fly ash consisting of chemical constituents such as $\mathrm{SiO}_{2}, \mathrm{Al}_{2} \mathrm{O}_{3}$, Feldspar, and Titanium are in

Table 1 Characterization of soil properties

\begin{tabular}{ll}
\hline Property & Value \\
\hline Natural moisture content, $\%$ & 16 \\
Specific gravity & 2.70 \\
Amount of finer material (<75 $\mu$ size), \% & 78 \\
Liquid limit, \% & 73 \\
Plastic limit, \% & 41 \\
Plasticity index, \% & 32 \\
Soil classification & $\mathrm{CH}$ \\
Optimum moisture content, $\%$ & 29 \\
Maximum dry density, $\mathrm{g} / \mathrm{cm}^{3}$ & 1.33 \\
Coefficient of consolidation, $\mathrm{cm}^{2} / \mathrm{min}$ & 0.024 \\
UCS, $\mathrm{kN} / \mathrm{m}^{2}$ & 50 \\
\hline
\end{tabular}

the proportion of $80,16,2$ and $2 \%$ by weight, respectively. The stabilising material called bottom ash used in this study shows the specific gravity of 2.2. The optimum water content of bottom ash was found to be $48 \%$ corresponding to the maximum dry density of $0.77 \mathrm{~g} / \mathrm{cm}^{3}$. Bottom ash consisting of chemical constituents such as $\mathrm{SiO}_{2}, \mathrm{Al}_{2} \mathrm{O}_{3}$, Feldspar, Calcium, Titanium and Iron are in the proportion of $79.8,14,2,0.69,1.6$ and $1.9 \%$ by weight, respectively. It indicates that the effective $95 \%$ ash material is contained with silica and alumina.

\section{Sample preparation and testing program}

Soft clay is mixed with different proportions of ash additives in the range of $10-40 \%$ by dry weight of the soil to make various soil combinations. Each soil combination was tested for its compaction properties to arrive the optimum water content corresponding to maximum dry density level. The test samples for consolidation and UCS were prepared at its maximum dry density level and OMC of each soil combination. A series of consolidation and UCS tests were performed on test samples as per the Indian standard test procedures.

\section{Results and discussion}

The compaction properties of all soil combinations are tested to obtain the OMC corresponding to its maximum density level. The influence of burnt ash additives on soft clay stabilisation by improving the consolidation and UCS properties is discussed. The sustainability of UCS with different curing times is also examined to quantify the improvement and proven it as innovative stabilised material. The combined effect of both the fly ash and bottom ash addition to the soft clay is also tested to compare the quantities of improvement by the addition of fly ash and bottom ash alone.

\section{Compaction properties}

Soft clay is mixed with four different percentages of ash amounts such as 10, 20, 30 and $40 \%$ by dry weight of the soil to obtain soil-burnt ash mixtures. Fly ash and bottom ashes are used as admixtures to make various soil combinations. Standard Proctor compaction tests were performed on different soil-ash mixtures as per the Indian standard test procedure according to IS: 2720-Part VII. The compaction curves are obtained for various soil-ash mixtures, and the influence of ash addition to the soft clay on OMC and maximum dry density levels is shown in Figs. 1, 2, 3 and 4. Effect of fly ash and bottom ash on compaction 


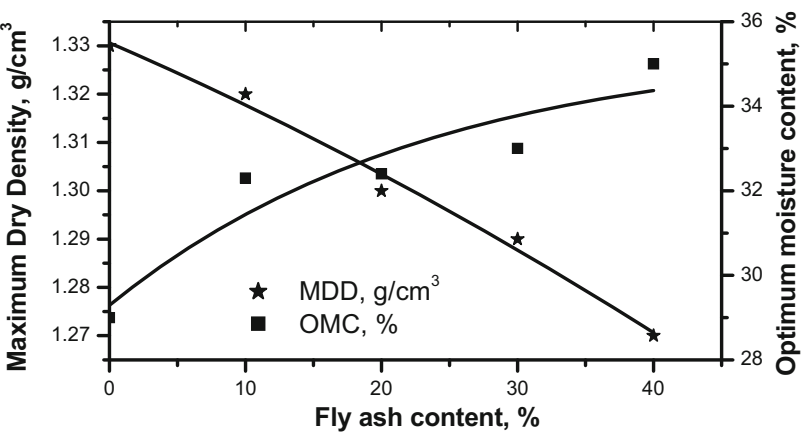

Fig. 1 Effect of Fly ash on compaction properties

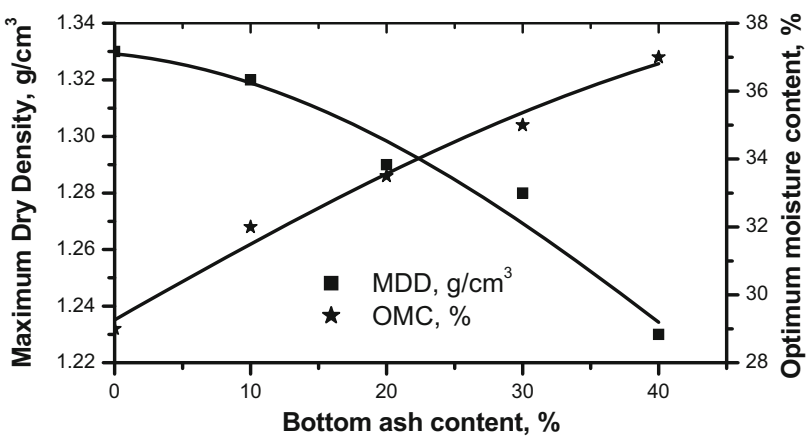

Fig. 2 Effect of Bottom ash on compaction properties

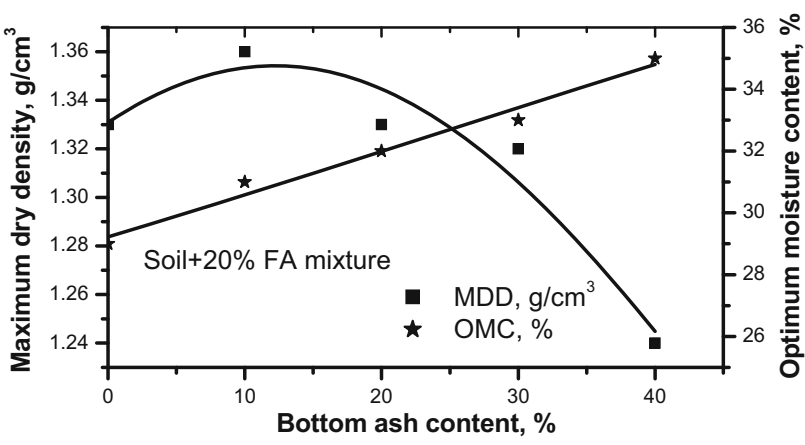

Fig. 3 Effect of BA on compaction of soil $+20 \%$ FA mixture

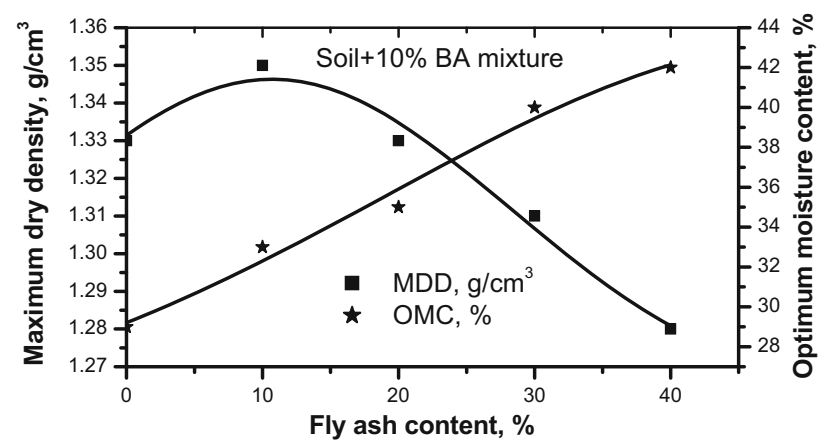

Fig. 4 Effect of FA on compaction of soil $+10 \%$ BA mixture properties of soft clay soil is shown in Figs. 1 and 2 respectively. Figure 3 demonstrates the effect of bottom ash in the range of $10-40 \%$ by weight on compaction properties of soil stabilised with $20 \%$ fly ash. Similarly, Fig. 4 indicates the effect of Fly ash in the range of $10-40 \%$ by weight on compaction properties of soil stabilised with $10 \%$ bottom ash. Figures 1, 2, 3 and 4 indicating the compaction parameters of the parent clay correspond to zero ash amounts. The trends are seen that the maximum dry densities are decreased and required optimum water contents are increased with increasing the additives to the soil irrespective of ash material. This trend may be expected due to the replacement of lightweight material which absorbs more water content.

\section{Consolidation properties}

The test samples placed in the consolidation ring were prepared at its maximum dry density level and OMC of each soil combination. A series of consolidation tests were performed on test samples of all soil combinations as per the Indian standard test procedure according to IS: 2720-Part XV. The consolidation test was repeated for different load increments for each test sample and squareroot of time plots were made for all test soil samples. Average values of coefficient of consolidation and time required for $90 \%$ consolidation are found for each test sample. The effect of ash addition to the soft clay on the coefficient of consolidation and time required for $90 \%$ consolidation is shown in Figs. 5, 6, 7 and 8. Effect of fly ash and bottom ash on consolidation properties of soft clay soil is shown in Figs. 5 and 6 respectively.

Figure 7 indicates the effect of bottom ash in the range of $10-40 \%$ by weight on consolidation properties of soil stabilised with $20 \%$ fly ash. Similarly Fig. 8 indicates the effect of Fly ash in the range of $10-40 \%$ by weight on consolidation properties of soil stabilised with $10 \%$ bottom ash. Figures 5, 6, 7 and 8 indicating the consolidation

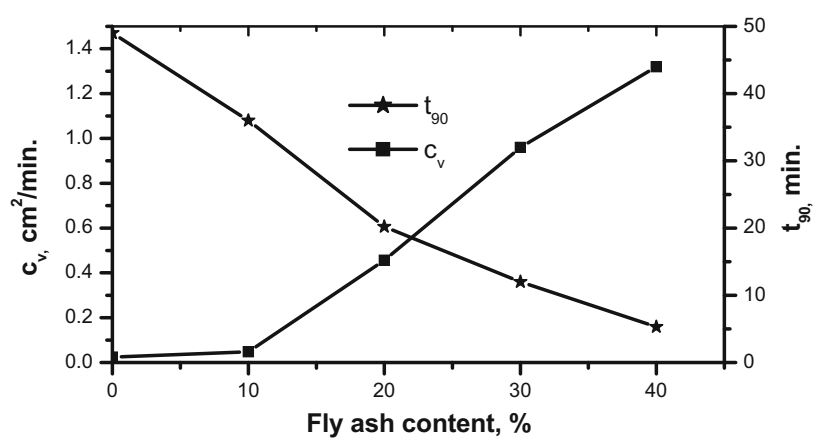

Fig. 5 Effect of fly ash on consolidation properties 


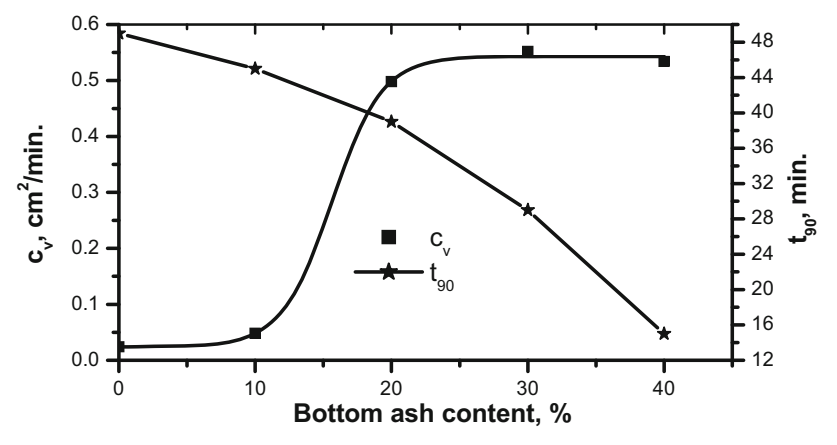

Fig. 6 Effect of bottom ash on consolidation properties

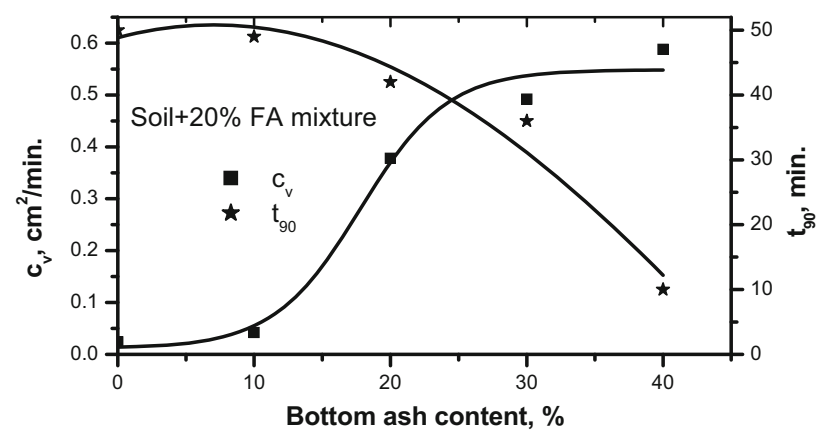

Fig. 7 Effect of BA on consolidation properties of soil $+20 \%$ FA mixture

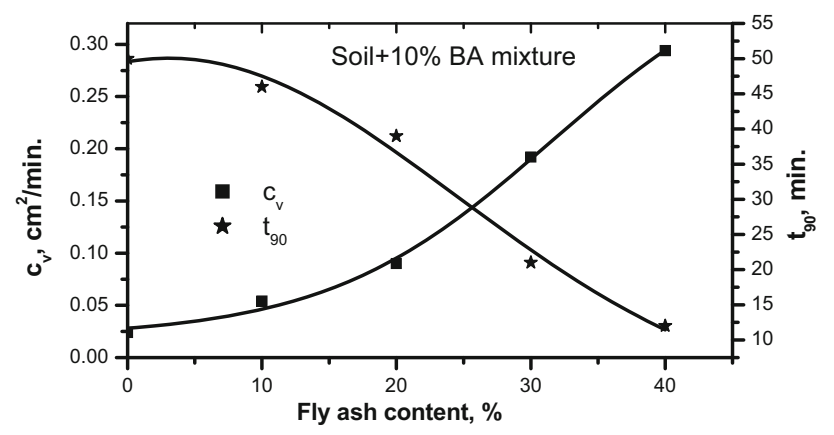

Fig. 8 Effect of FA on consolidation of soil $+10 \%$ BA mixture

parameters of the parent clay correspond to zero ash amounts. The similar trend of relations is observed in-between the ash contents and consolidation parameters irrespective of the type of additives. The coefficient of consolidation is increased and the time required for $90 \%$ consolidation is decreased with the addition of ash material to the soil. The increasing trend of $c_{v}$ may be due to the nature of silt and sand size of ash particles which makes the soil more permeable and allows faster drainage and hence accelerate or decrease the time required for $90 \%$ consolidation.

\section{Unconfined compressive strength}

The UCS cylindrical test samples of $38 \mathrm{~mm} \times 76 \mathrm{~mm}$ size were cast at its maximum dry density level and OMC of each soil combination. A series of UCS tests were performed on test samples of all soil combinations as per the Indian standard test procedure according to IS: 2720-Part $\mathrm{X}$. Unconfined compression test was repeated in thrice for each test sample to obtain the average maximum strength value. The effect of ash addition to the soft clay on UCS value at 28 days of curing time derived from stress-strain curves made for all test soil samples as shown in Fig. 9. Figure 9 indicating the UCS of the parent clay corresponds to zero ash amounts. Herein, test soil samples containing soil combinations of soil-fly ash mixtures, soil-bottom ash mixtures, soil stabilised with $20 \%$ fly ash-bottom ash mixtures, and soil stabilised with $10 \%$ bottom ash-fly ash mixtures.

In the case of soil-fly ash mixtures, the unconfined compressive strength is much more than other soil combinations. The figure is indicating $20 \%$ fly ash as an optimal level of fly ash added to the soil corresponding to the highest UCS value of $242 \mathrm{kPa}$. Beyond $20 \%$ fly ash, the strength may decrease due to loosening the strong matrix between the clay and fly ash particles. Quantitatively, the strength was improved about 4.86 times over the strength of clay soil. The strength of clay has also improved with the addition of bottom ash up to $10 \%$ into the clay soil, and the improved strength is about 3.18 times the strength of the clay soil. Beyond $10 \%$ bottom ash, the strength is drastically decreased with increase in the ash content and the clay lost its original strength after addition of $40 \%$ bottom ash. It may be due to increasing of porous voids and less compressibility of ash particles. The increase in strength is reduced to 0.66 times the strength of soil-fly ash mixture at an optimum level of $20 \%$ fly ash. It may be due to less compressible nature of bottom ash.

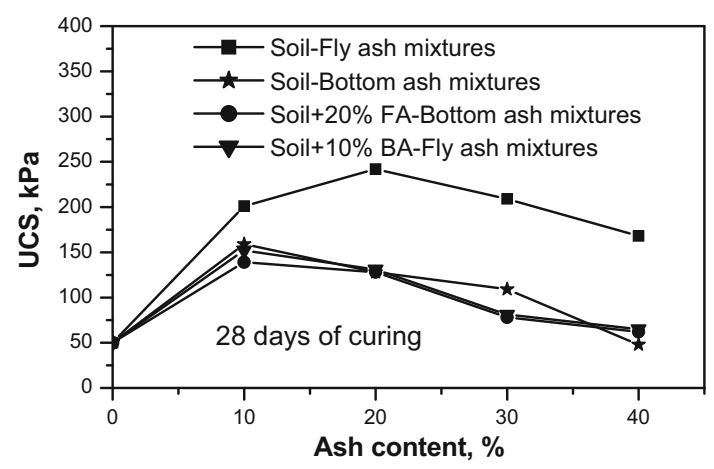

Fig. 9 Effect of ash content on UCS value of soil-ash mixtures 
Table 2 Effect of curing time on UCS values of various soilash mixtures

\begin{tabular}{|c|c|c|c|c|c|}
\hline \multirow[t]{2}{*}{ Soil-ash mixtures } & \multicolumn{5}{|c|}{ UCS values at the curing time, $\mathrm{kPa}$} \\
\hline & 1 day & 3 days & 7 days & 14 days & 28 days \\
\hline Untreated soil & 50 & 50 & 50 & 50 & 50 \\
\hline \multicolumn{6}{|l|}{ Soil-fly ash mixtures } \\
\hline FA content, $10 \%$ & 176 & 180 & 189 & 196 & 201 \\
\hline $20 \%$ (optimum) & 212 & 223 & 235 & 240 & 242 \\
\hline $30 \%$ & 145 & 198 & 202 & 207 & 209 \\
\hline $40 \%$ & 125 & 155 & 164 & 167 & 168 \\
\hline \multicolumn{6}{|l|}{ Soil-bottom ash mixtures } \\
\hline BA content, $10 \%$ (optimum) & 114 & 150 & 153 & 156 & 159 \\
\hline $20 \%$ & 105 & 113 & 122 & 125 & 128 \\
\hline $30 \%$ & 82 & 90 & 102 & 105 & 109 \\
\hline $40 \%$ & 38 & 40 & 43 & 45 & 48 \\
\hline \multicolumn{6}{|c|}{ Soil $+20 \%$ FA-bottom ash mixtures } \\
\hline BA content, $10 \%$ (optimum) & 111 & 129 & 135 & 137 & 139 \\
\hline $20 \%$ & 93 & 101 & 125 & 126 & 128 \\
\hline $30 \%$ & 91 & 96 & 74 & 77 & 78 \\
\hline $40 \%$ & 68 & 77 & 63 & 62 & 62 \\
\hline \multicolumn{6}{|l|}{ Soil $+10 \%$ BA-fly ash mixtures } \\
\hline FA content, $10 \%$ (optimum) & 117 & 134 & 143 & 150 & 152 \\
\hline $20 \%$ & 103 & 105 & 108 & 129 & 131 \\
\hline $30 \%$ & 99 & 57 & 65 & 80 & 81 \\
\hline $40 \%$ & 87 & 47 & 55 & 64 & 65 \\
\hline
\end{tabular}

Figure 9 shows the effect of bottom ash in the range of $10-40 \%$ by weight on UCS properties of soil stabilised with $20 \%$ fly ash. Similarly, Fig. 9 also indicates the effect of Fly ash in the range of $10-40 \%$ by weight on UCS properties of soil stabilised with $10 \%$ bottom ash. Herein, the optimal dosages of fly ash and bottom ashes are fixed at 20 and $10 \%$, respectively, those arrive after testing on soil-fly ash and soil-bottom ash mixtures. UCS tests were conducted on soil-fly ash-bottom ash mixtures to examine the combined effect of fly ash and bottom ash on strength improvement of clay soil.

It is observed from Fig. 9 that the soil stabilised with $20 \%$ fly ash mixed with bottom ash levels possess the maximum unconfined compression strength of $139 \mathrm{kPa}$ at optimal bottom ash content of $10 \%$. Quantitatively, the strength was improved about 2.78 times the strength of clay soil. However, the increase in strength of this soil mixture is reduced to 0.57 times the strength of soil stabilised with $20 \%$ fly ash.

It can be seen from Fig. 9 that the soil stabilised with $10 \%$ bottom ash mixed with fly ash levels possess the maximum unconfined compression strength of $152 \mathrm{kPa}$ at optimal fly ash content of $10 \%$. Quantitatively, the strength was improved about 3.1 times the strength of clay soil. However, the increase in strength of this soil mixture is reduced to 0.62 times the strength of soil stabilised with
$20 \%$ fly ash. This result is also indicating that there is no significant effect on the addition of fly ash over the UCS of soil stabilised with $10 \%$ bottom ash.

The sustainability of UCS of different soil-ash mixtures is examined with various curing times as presented in Table 2. It is manifestly illustrated that the UCS values are increasing with increase in the curing time from 1-28 days in cases of soil-ash mixtures. The increase in strength with curing may be possible due to the strong cementation property of fly ash or bottom ash alone in the presence of continuous moisture. However, the soil stabilised by using both the fly ash and bottom ash additives at 30 and $40 \%$ ash levels, the strength decrease is observed with curing time. It may be due to loosening the cementation effect by the combination of both the fly ash and bottom ashes at high levels in the presence of moisture.

\section{Conclusions}

A series of laboratory tests was performed on various soil combinations to study the influence of ash additives on stabilisation of soft clay and the main findings arrived at:

- The coefficient of consolidation is increased and the time required for $90 \%$ consolidation is decreased with 
the addition of ash material to the soil. The increasing trend of $c_{\mathrm{v}}$ may be due to the nature of silt and sand size of ash particles which makes the soil more permeable and allows faster drainage and hence accelerate or decrease the time required for $90 \%$ consolidation.

- The soil stabilised with $20 \%$ fly ash alone is the best soil combination which exhibits the UCS about 4.86 times the strength of clay soil.

- Improved strength in the case of soil stabilised with $10 \%$ bottom ash alone was about 3.18 times the strength of the clay soil. It indicates the increase in strength reduced to 0.66 times the strength of soil stabilised with $20 \%$ fly ash alone. It may be due to less compressible nature and more porous structure of bottom ash.

- The soil stabilised with $20 \%$ fly ash mixed with $10 \%$ bottom ash content possess the UCS about 2.78 times the strength of clay soil. Similarly, the soil stabilised with $10 \%$ bottom ash mixed with $10 \%$ fly ash possess the UCS about 3.1 times the strength of clay soil.

- The combined effect of both the fly ash and bottom ash addition to the soft clay is not efficient when compared to the strength improvement of clay soil by adding either fly ash or bottom ash alone.

- The UCS is increasing with increase in curing time irrespective of all soil-ash mixtures. It may be possible due to the strong cementation property of fly ash or bottom ash alone in the presence of continuous moisture.

In conclusion, fly ash is more efficient in stabilizing the soft ground while comparing with the bottom ash.

\section{References}

1. Muhardi AM, Kassim KA, Makhtar AM, Lee FW, Yap SL (2010) Engineering characteristics of Tanjung Bin coal ash. Electron J Geotech Eng 15:1117-1129

2. Bhuvaneshwari S., Robinson RG, Gandhi SR (2005) Stabilisation of expansive soils using fly ash. Fly Ash India 2005, New Delhi, DST Project report

3. Cokca Erdal (2001) Use of class C fly ashes for the stabilization of an expansive soil. J Geotech Geoenviron Eng 127:568-573

4. Sharma RK, Singh B (2013) Modification of clayey soil using fly ash. Int J Res Eng Technol 02:356-361

5. Brooks RM (2009) Soil stabilisation with fly ash and rice husk ash. Int J Res Rev Appl Sci 1(3):209-217

6. Vaishali S, Gayathri V (2014) Strength studies of Dadri fly ash modified with lime sludge - a composite material. Int $\mathrm{J}$ Eng Technol 4(3):161-169

7. Aminaton M, Muzamir H, Masayuki H, Ahmad MM (2014) Shear strength parameters and consolidation of clay reinforced with single and group bottom ash columns. Arab J Sci Eng 39:2641-2654

8. Das SK, Yudhbir (2005) Geotechnical characterization of some Indian flyashes. J Mater Civil Eng ASCE 17(5):544-552

9. Huang HW (1990) The use of bottom ash in highway embankments, subgrade and subbases. Joint Highway Research Project, FHWA/IN/JHRP-90/4, Indiana

10. Kumar S, Stewart J (2003) Geotechnical engineering characteristics of Illinois PCC dry bottom ash amended with bentonite. ASCE J Energy Eng 129(2):401-415

11. Muzamir BH, Aminaton M, Masayuki H, Ahmad MM (2011) The strength of soft clay reinforced with singular and group bottom ash columns. Electron J Geotech Eng 16:1215-1227 